\title{
EARTHQUAKE IN HAITI AND DISASTER MEDICINE TRAINING
}

\author{
Romanova Hr. ${ }^{1}$, I. Marinova ${ }^{1}$, N. Radeva ${ }^{2}$, M. Marinov ${ }^{3}$ \\ ${ }^{1}$ Departmet of Hygiene and Disaster Medicine, Medical University - Varna \\ ${ }^{2}$ Department of Health Management, Medical University - Varna \\ ${ }^{3}$ Department of Preclinical and Clinical Sciences, Medical University - Varna
}

Reviewed by: assoc. prof. B. Yustinianova

\begin{abstract}
Inquiry research is made among medical students - 100 persons from Medical University - Varna at the end of 2010 with questionnaire containing 10 questions for determining the level of knowledge about disastrous situations. From the research we determine that $52 \%$ consider the Haiti earthquake like the heaviest disaster in the world, 39\% point the Pakistan floods, $5 \%$ - other disastrous situations (volcano activities) and $4 \%$ - can not determine. The majority $95 \%$ answer that they want to help the sufferers but only $41 \%$ were donated in the donation campaigns, organized by different, mainly TV shows presenters. The prognosis for the consequences of the Haiti earthquake is unfavorable for $51 \%$ from the participants.
\end{abstract}

Key words: disastrous situation, Haiti earthquake, disaster medicine

\section{INTRODUCTION}

Disasters are sudden events, which seriously disturb our daily, threaten the lives and health of large groups of people $(1,2,3)$. The earthquake in Haiti 2010 happened in 12.01.2010 at 16h $53 \mathrm{~min}$ at local time. Magnitude was 7.0 to 7.3 , the country's most severe earthquake in over 200 years. It left between 250000 people dead, 300000 wounded and 1.6 million homeless. The epicenter was at $25 \mathrm{~km}$ from Port-au-Price (the capital) and the duration was 2 min 30 sec. In the following hours there were 12 secondary tremors, but weaker. A second earthquake occurs with magnitude of 6.1 on 20.01 .2010 at $06 \mathrm{~h} 03 \mathrm{~min}$ at $59 \mathrm{~km}$ from Port-au-Prince $(4,5,6,7)$.

The structure and organization of the Haitian state have suffered from the incident after 3 days, the state of emergency was declared throughout the country for a month. Numerous buildings were also destroyed, including the National Palace and Notre Dame de Port-au-Prince. According to institute of Geological Studies US, the earthquake would have had a magnitude of 7 (equivalent to the energy released by an H-bomb of about 5 million tonnes). There was also a series of aftershocks, respectively 5.9, 5.5 and 5.1 .

Our goal is to research the opinion of students from the Medical university - Varna which is the heaviest disaster during 2010 and their knowledge about this problem.

\footnotetext{
Address for correspondence:

I. Marinova, Dept. of Hygiene and Disaster Medicine

Medical University - Varna, Marin Drinov str. 55, Varna

e-mail: marinovaig@abv.bg
}

\section{MATERIALS AND METHODS}

Research is made among medical students - 100 persons from Medical University - Varna at the end of 2010 with questionnaire containing 10 questions for determining the level of knowledge about disastrous situations.

The half of the questions is with preliminary formulated answers and the other part is opened questions with possibilities for personal opinion.

Table 1. Participants in the research.

\begin{tabular}{||c|c|c|c|c|c|c||}
\hline \hline Age & \multicolumn{2}{|c|}{$18-22$} & \multicolumn{2}{c|}{$23-27$} & Total & $\%$ \\
\hline Men & 25 & $25 \%$ & 6 & $6 \%$ & 31 & 31 \\
\hline Women & 61 & $61 \%$ & 8 & $8 \%$ & 69 & 69 \\
\hline
\end{tabular}

It is executed the principle of the same attitude for the all participants.

The machining data processing is made.

\section{RESULTS AND DISCUSSIONS}

The participants in the research are $2 / 3$ women and $1 / 3$ men and this correspond to the students from the Medical university - Varna, where the predominated is female gender (Table 1).

From the research we determine that $52 \%$ consider the Haiti earthquake like the heaviest disaster in the world, $39 \%$ point the Pakistan floods, $5 \%$ - other disastrous situations (volcano activities) and 4\% - can not determine (Fig. 1). 
The half of the inquired is informed about previous earthquakes in Haiti.

Previous earthquakes of high intensity occurred in Haiti include those that occurred in 18.10.1751 and 03.06.1770. The historian Moreau de St. Mery reports that in Port-au-Prince in 1750 "one of the houses of masonry was not reversed", and in 1770 "the whole town was reversed". After this there were another strong earthquakes in 1842, 1887, 1904.

The first aftershock in the 2010 earthquake, occurred 19 minutes after the first shock, suggesting a worsening of the situation given the inability to implement first aid in the minutes following the incident.

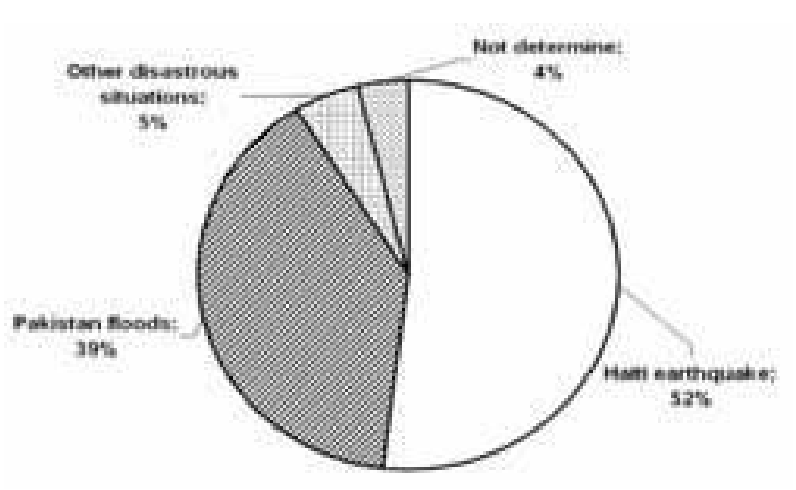

Fig.1. The heaviest disaster during 2010.

The magnitude of these replicas, approaching 6, is also another factor, rare in this type of event, calling it a major disaster: by definition, the effects of aftershocks "can cause major damage to poorly designed buildings in areas restricted. Cause slight damage to well-designed buildings." The island of Hispaniola (shared by Haiti and the Dominican Republic) is located in a seismically active zone between 2 tectonic plates: the North American Plate to the north and south Caribbean plate.

Just after the earthquake in 2010, great clouds of dust appeared in the moments after the earthquake in Port-au-Prince. This dust is likely due to unreinforced concrete buildings; accumulates fears about the possibility that many such buildings have collapsed. Poor country, Haiti has no formal construction standards for buildings.

The cities of Carrefour (300 000 inhabitants, destroyed at 40\%), Leogane (200 000 inhabitants, destroyed more than $90 \%$ ) and Gressier, near the quake's epicenter, was severely affected.

The only positive fact after the earthquake was that the airport in the capital was practicable, permitting to bring by air the helping people, the materials for emergency and the logistic.

Ban Ki-moon, Secretary General of the UN estimated that some 3 million people could be affected over 4 million in the population of Port-au-Prince.

The destruction of thousands of homes and fear of aftershocks since then have pushed most of the inhabitants of the city to spend the night outside. The survivors have no or little water, food and medicines. Until 13 January, the field hospital of the Argentine Air Force, installed as part of the UN since 2004, was the only on-site operational.

January 20, another earthquake of magnitude 6.1 was felt again and an immediate consequence, a massive exodus has been observed.

The earthquake has left the only feasible path to the airport, but the tower was destroyed. The first landings have been monitored since the airports of the Dominican Republic.

The first days after the disaster, jumbo jets could not land on the runway. It was therefore necessary that their contents are transshipped on the airfields of the Dominican Republic, on airplanes of smaller size, allowing them to flow through the airport in Haiti.

The port is useless, and the four cranes are unusable, and this exacerbates the logistical problems for the movement of material and human means of help.

On site, delivery of food and water survival itself is difficult. The Haitian population lives usually two days in advance of food pantries, places of life destroyed for the most part, is its almost total destitution.

The difficulty of transmission is also illustrated in road infrastructure, for example to connect the coastal cities of South East Department, located south of Port-au-Prince, Jacmel such, also hard hit, you have to take a road strewn with boulders and tree trunks that only manages to avoid by a motorcycle.

On the fourth day after the earthquake, refugees fleeing Haiti by sea, like boat people, were observed.

On the sixth day after the earthquake, about 70000 bodies had been buried, mostly in mass graves.

Neither morgues and cemeteries do not have sufficient capacity to manage the scale of casualties recorded: firstly extracted the bodies from the rubble had been gathered in town squares and on along the road. Confronted with television images showing the promiscuity of the survivors and the dead in the city, commentators from the Haitian diaspora, said the events would mark a long time the trauma of the nation.

Health conditions require burial in mass graves, which opposes the practices in Haiti. In addition, Haitian voodoo priests opposed to the methods of burial in mass graves, arguing that they do not respect the dignity of the deceased. Drinkable water: UNICEF works for the distribution of drinking water, as in the town of Fonds-Parisien, located near the brackish ponds and the border with the Dominican Republic.

Food Assistance: staple foods such as rice can not be considered to feed the population, who lost the usual means to cook with the destruction of places of life. Supply lavished by humanitarian aid has privileged food rations compact providing the necessary nutritional rations should provide power to the affected population in the coming weeks.

The means of the state to deal with the event are even more limited than in Haiti is the 149th (out of 182) in the human development index. That is why a large force of military forces was deployed on the ground to support and secure delivery of humanitarian aid and prevent overflows. 
Several countries, large global corporations and celebrities have made many donations to help the Haitian people. The majority $95 \%$ from the inquired answer that they want to help the sufferers but only $41 \%$ were donated in the donation campaigns, organized by different, mainly TV shows presenters.

Many problems remain, in more there is outbreak of cholera, which caused protests against the U.N. peacekeeping forces led to violent attacks on November 15.2010 forces suspected them of bringing the cholera strain to Haiti. The cholera outbreak had, at that point, killed more than 2100 people since mid-October, and sickened around 15000. The strain may have come from the Nepalese peacekeepers, who have a base on the Artibonite river, but the U.N. does not want people to come to conclusions and blame the Nepalese based on "misinformation". However, the last cholera outbreak in Haiti was forty years ago, and "The U.S. Centers for Disease Control and Prevention found that the cholera strain now ravaging the country matched a strain specific to South Asia, but said they had not pinpointed its origin or how it arrived in Haiti."

The half of the participants (51\%) considers that the unfavorable consequences from the Haiti earthquake 2010 will continue $4-5$ years after the disaster, $32 \%$ consider that the situation will be overcame for $1-2$ years thanks of the international help, $17 \%$ can not make a prognosis (Fig. 2.).

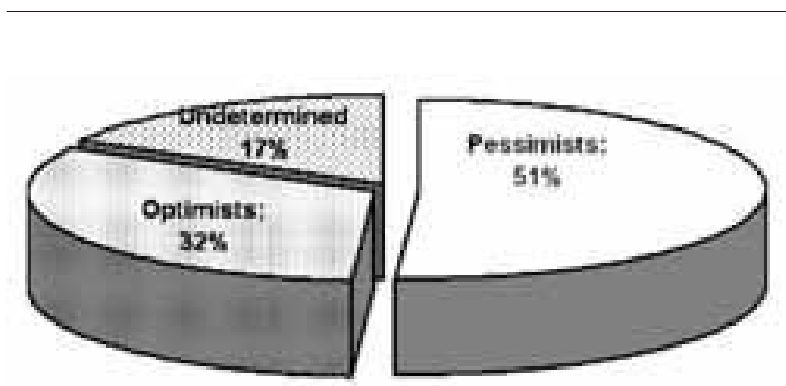

Fig. 2. Prognosis for overcoming the consequences of

the earthquake.

\section{CONCLUSION}

1. From the research we determine that $52 \%$ consider the Haiti earthquake like the heaviest disaster in the world, $39 \%$ point the Pakistan floods, $5 \%$ - other disastrous situations /volcano activities/ and 4\% - can not determine.

2. The cholera's consequences are heavier than the earthquake's consequences.

3. The prognosis for the earthquake's consequences is unfavorable for $51 \%$ from the participants.

\section{REFERENCES}

1. Romanova Hr., Disaster medicine (Manual for medical students), Medical University, Varna, 2007

2. WHO, Community emergency preparedness, Geneva, 1999

3. WHO, International trial and health, Geneva, 2004

4. http://www.insu.cnrs.fr/a3348, seisme-haiti-12-janvier2010.html

5. http://www.20min.ch/ro/news/monde/story/150-000 -morts-confirmees-par-le-gouvernement-31195405

6. http://www.lefigaro.fr/flash-actu/2010

7. http://www.lemonde.fr/ameriques/article/2010/02/19 